\title{
TEM and SAED Characterization of Metakaolin. Pozzolanic Activity
}

\author{
L. Trusilewicz, ${ }^{\ddagger \dagger}$ F. Fernández-Martínez, ${ }^{\ddagger}$ V. Rahhal ${ }^{\S}$ and R.Talero \\ ‡Escuela Técnica Superior de Ingeniería y Diseño Industrial, Universidad Politécnica de Madrid, 28012 Madrid, Spain \\ ${ }^{\S}$ Civil Engineering Department, Faculty of Engineering, U.N.C.P.B.A, Avda. del Valle 5737, B7400JWI Olavarría, Argentina \\ "Instituto de Ciencias de la Construcción "Eduardo Torroja", Consejo Superior de Investigaciones Científicas, \\ 28033 Madrid, Spain
}

\begin{abstract}
The present study deals with a characterization of metakaolin pozzolanic activity and its chemical character exhibited in the Ordinary Portland Cement (OPC) blends by means of Transmission Electron Microscopy (TEM) and Selected-Area Electron Diffraction (SAED) techniques principally. Metakaolin sample was prepared by calcination of kaolin rock (Guadalajara, Spain) at $780^{\circ} \mathrm{C}$. Two OPC of different chemical composition from the tricalcium aluminate content point of view were chosen and Portland cement blends series elaborated and then submitted to the pozzolanic activity test (EN 196-5 or Frattini test). The main mineralogical components of the metakaolin are determined qualitatively: $\chi$-alumina and quartz. The chemical character of the metakaolin is described because of its final composition as well as due to its Al atoms possible coordination. The crystalline order of the material is found to be of both amorphous and polycrystalline, being an intimate amorphous mixture of alumina and silica. Finally, all the alumina capable of reacting chemically is denominated and classified as reactive alumina component, $\mathrm{Al}_{2} \mathrm{O}_{3}{ }^{\mathrm{r}-}$, of pozzolans, as well as the aluminic chemical character of metakaolin in OPC blends is once again proved and exhibited by means of Friedel's salt formation studied already at $4 \mathrm{~h}$-age.
\end{abstract}

\section{Introduction}

$\mathrm{K}$ AOLIN rock is classified to a mineral group composed by clays or clayey rocks, generally of detritus kind. These minerals possess a different crystalline structure between each other (kaolinite, illite, montmorillonite), but are constituted by subsequent sheet of $\mathrm{Si}$ tetrahedral and $\mathrm{Al}$ octahedral.

The most attractive properties of clayey minerals from their usefulness for Portland cement (PC) industry are those achieved thanks to their usually programmed, thermal treatment which gives rise to new semi-crystalline/amorphous compounds, conserving their original crystalline structure or not. Kaolinite, $2 \mathrm{SiO}_{2} \cdot \mathrm{Al}_{2} \mathrm{O}_{3} \cdot 2 \mathrm{H}_{2} \mathrm{O}$, $\left(\mathrm{S}_{2} \mathrm{AH}_{2}\right.$ in cement nomenclature, i.e., $\mathrm{S}-\mathrm{SiO}_{2}, \mathrm{~A}-\mathrm{Al}_{2} \mathrm{O}_{3}, \mathrm{H}-\mathrm{H}_{2} \mathrm{O}$ ), heated at given conditions is converted into metakaolinite, $2 \mathrm{SiO}_{2} \cdot \mathrm{Al}_{2} \mathrm{O}_{3},\left(\mathrm{~S}_{2} \mathrm{~A}\right)$. In other words, it becomes the intermediate artificial reactive product resultant from adequate thermal dehydroxylation $\left(\mathrm{OH}^{-}\right.$groups loss) of the kaolinite crystalline lattice that begins at $550^{\circ} \mathrm{C} .{ }^{13}$ Whereas the heating continues at higher temperatures, new properties of the materials can be achieved, modified and also designed. ${ }^{4}$ As an example, the solubility in acids ( $\mathrm{HCl}$ or $\mathrm{HF})$ can be modified, which is an important parameter from the material pozzolanic activity point of view, since, as demonstrated previously, 5,6 the nonsoluble quantities of clay are not capable of reacting with portlandite (a main Portland cement hydration products) and/or calcium hydroxide.

The thermal transformation mechanism of kaolin and a subsequent new properties achievement by its resultant metakaolin has been described by several authors. ${ }^{2,69}$ When all the dehydroxylation water is out from the original crystalline lattice of kaolin, the new reactive transitional structure is conserved (metakaolinite). ${ }^{2}$ However, a certain disagreement still exists to assign any particular crystal structure to this transitional state. According to Brindley and Nakahira, ${ }^{10}$ the $\mathrm{Al}^{3+}$ and $\mathrm{Si}^{4+}$ cations maintain their reticular positions, but report a different coordination to oxygen anions. Taylor ${ }^{1}$ claims that the oxygen possesses some specific disposition to be bonded randomly to the cations $\mathrm{Al}^{3+}$ and $\mathrm{Si}^{4+}$, considering the mentioned proton migration essential for the resultant structure of metakaolin. Freund ${ }^{11}$ sustains an elevated concentration of reticular defects in the structure and also combined with tetrahedral coordination of $\mathrm{Al}$, therefore it is impossible to assign any determined structure of such a metastable level.

Finally, the only certainty obtained so far is that metakaolin conserves some part of original crystalline structure, socalled "crystalline memory" of its kaolinite precursor, ${ }^{2}$ denominated its thermal activation as "topologic transformation" of original clayey mineral. However, Jaffee ${ }^{11}$ presents some assumptions based on experimental chemical reactivity of metakaolinite, formulating an idea that it possesses fixed bounds of $\mathrm{Si}-\mathrm{O}-\mathrm{Al}$, although somewhat weaker than those of its precursor kaolin. Therefore, their complete separation during acid-basic attacks can be achieved, for instance, by means of Florentin method. ${ }^{1}$

Finally, from the Cement Chemistry point of view, Talero ${ }^{12}$ denominates the active and/or reactive (mostly amorphous or different ones from the crystalline and vitreous fraction) part of the OPC pozzolanic mineral additions (i.e., metakaolin, silica fume, fly ash, natural pozzolans from volcanic origin) as: reactive silica, $\mathrm{SiO}_{2}{ }^{\mathrm{r}-}$, reactive alumina, $\mathrm{Al}_{2} \mathrm{O}_{3}{ }^{\mathrm{r}-}$ and reactive ferric oxide, $\mathrm{Fe}_{2} \mathrm{O}_{3}{ }^{\mathrm{r}-}$, in a respective case. In addition and from the point of view of the Chemistry of Cement, this component is commonly termed "hydraulic factor" of the pozzolanic material, being the principal fraction involved in its chemical reactivity, $\mathrm{SiO}_{2}{ }^{\mathrm{r}-}$ and $\mathrm{Al}_{2} \mathrm{O}_{3}{ }^{\mathrm{r}-}$ especially, in the hydraulicity of its cement paste blended with Portland cement. The mentioned denomination has been successfully applied and developed in numerous studies during over 25 last years, (the most significant researches dealt with chemical attacks to Portland Cement blended with pozzolans, caused mainly by sulfates, ${ }^{7,8,12}$ chlorides, ${ }^{9}$ sea water, carbonation, ASR, etc.), and this terminology continues to be employed in this study as well. 
Talero's considerations ${ }^{12}$ about the classification used for the reactive fractions of pozzolans, as a mineral partial substitute for Portland cement, have been supplemented by Moya et al. ${ }^{13} 2$ years later. Those observations of kaolinite dehydroxylation process delivered that reactive alumina, $\mathrm{Al}_{2} \mathrm{O}_{3}{ }^{\mathrm{r}-}$, studied by Talero in $\mathrm{PC} / \mathrm{MK}$ blends, ${ }^{7,12}$ corresponds to tetra- and penta-coordinated alumina of metakaolin, characterized by its physicochemical amorphous state, ${ }^{13}$ principally.

Pozzolanic activity of these active mineral admixtures consists of a chemical reaction of their "hydraulic factors", $\mathrm{SiO}_{2}{ }^{\mathrm{r}-}$ and $\mathrm{Al}_{2} \mathrm{O}_{3}{ }^{\mathrm{r}-}$, with portlandite, $\mathrm{Ca}(\mathrm{OH})_{2}$, (released from Portland cement hydration), to generate new phases of cementitious properties. ${ }^{14}$ Moreover, a given pozzolanic material should fulfill the following chemical condition ${ }^{15}$ : $\mathrm{SiO}_{2 \text { (total) }}+\mathrm{Al}_{2} \mathrm{O}_{3 \text { (total) }}+\mathrm{Fe}_{2} \mathrm{O}_{3 \text { (total) }} \geq 70 \mathrm{wt} \%$.

\section{Objectives}

The main objective of this study was the morphological characterization of metakaolin (MK), taking into account its crystalline degree aspect and thermal evolution especially, related directly to its high pozzolanic activity in its OPC blends and the chemical character involved.

\section{Experimental Procedure}

The experimental part of this work consisted first of a MK sample preparation by calcination process of kaolin rock at $780^{\circ} \mathrm{C}(24 \mathrm{~h})$ in air atmosphere, being the most appropriate temperature to obtain the most reactive chemically material as indicated by previous authors. ${ }^{11}$ For this purpose, the high purity raw material was selected from Guadalajara region (Spain). Moreover, to compare, two OPC of different mineralogical composition from the tricalcium aluminate, $\mathrm{C}_{3} \mathrm{~A}$, and tricalcium silicate, $\mathrm{C}_{3} \mathrm{~S}$, content point of view, $(\mathrm{C}-\mathrm{CaO}$, $\left.\mathrm{A}-\mathrm{Al}_{2} \mathrm{O}_{3}, \mathrm{~S}-\mathrm{SiO}_{2}\right), \mathrm{PC} 1$ and $\mathrm{PC} 2$, were chosen. The elaborated Portland cement blends series were then submitted to the pozzolanicity test ${ }^{16}$ (EN 196-5 of obligatory compliance for pozzolanic cements ${ }^{17}$ ), Fig. 1. This standard procedure of pozzolanic cements, so-called Frattini test ${ }^{16}$ consists of the quantitative determination of $\mathrm{Ca}(\mathrm{OH})_{2}$ concentration, released from PC during hydration reaction process, which is carried out in aqueous solution containing the hydrated sample, once a given time is passed $(2,7$, and 28 days in this study). The collected data are presented together with the calcium hydroxide, $\mathrm{Ca}(\mathrm{OH})_{2}$, solubility isotherm estimated for an alkaline solution at $40^{\circ} \mathrm{C}$. The correspondent point $\left[\mathrm{CaO} ; \mathrm{OH}^{-}\right]$placed below the solubility isotherm indicates positive result of the test, i.e., points out pozzolanic activity of the tested addition (MK). The selected replacement dosages used in this study for the PC/MK blends were $80 / 20$ and $60 / 40 \mathrm{wt} \%$. The obtained results are present in Fig. 1.

The chemical composition of the materials, MK and PC, is given in Table I and it was achieved by means of ASTM C311 18 and EN 196-2 $2^{19}$ procedures, respectively. The specific area $\mathrm{BET}$ was determined by $\mathrm{N}_{2}$ adsorption method in isothermal conditions at $77 \mathrm{~K}$. The potential composition of $\mathrm{PC}, \mathrm{PC} 1$, and $\mathrm{PC} 2$, using the Bogue's formulas, ${ }^{20}$ was as follows: $51 \% \mathrm{C}_{3} \mathrm{~S}, 16 \% \mathrm{C}_{2} \mathrm{~S}, 14 \% \mathrm{C}_{3} \mathrm{~A}$, and $5 \% \mathrm{C}_{4} \mathrm{AF}$ for $\mathrm{PC} 1$ (OPC), and $79 \% \mathrm{C}_{3} \mathrm{~S}, 2 \% \mathrm{C}_{2} \mathrm{~S}, 0 \% \mathrm{C}_{3} \mathrm{~A}$, and $10 \% \mathrm{C}_{4} \mathrm{AF}$ for $\mathrm{PC}$, respectively.

Thermal Analysis (TA) of the MK as well as of its precursor, kaolin, was performed (Figs. 2 and 3). Non-isothermal decomposition of the sample was determined with SDT Q600 TA Instruments thermogravimeter (WATERS, Madrid, Spain), under the $\mathrm{N}_{2}$ dynamic flow. The experiment was carried out up to $1100^{\circ} \mathrm{C}$ with a heating rate of $10^{\circ} \mathrm{C} / \mathrm{min}$. The sample weight applied did not exceed $50 \mathrm{mg}$, (Pt sample holder). The thermal transformation stages were correspondently assigned and kinetics models calculated for the kaolin dehydroxylation by means of the Coats \& Redfern approxi-

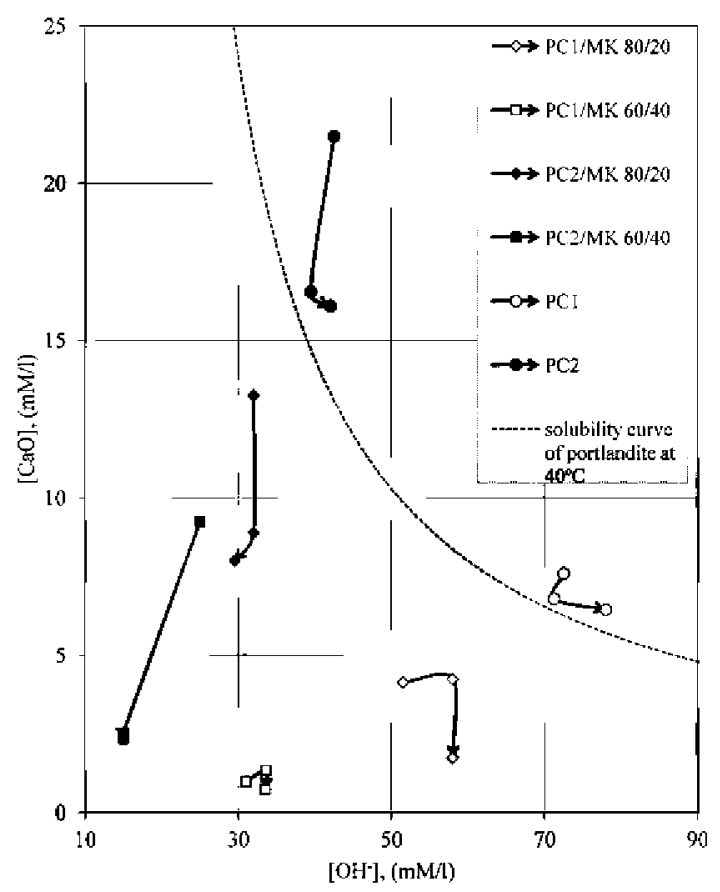

Fig. 1. Frattini results for PC1 and PC2 cements blended with the metakaolin (MK). Hydration reaction at 2, 7, and 28 days-age.

Table I. Chemical Composition of MK (ASTM C311 ${ }^{18}$ ) and the Cements, PC1 and PC2 (EN 196-2 ${ }^{19}$ )

\begin{tabular}{lrcc}
\hline & \multicolumn{1}{c}{ MK } & PC1 & PC2 \\
\hline Material/Parameter & & & \\
$\mathrm{LOI} \%$ & 0.46 & 1.60 & 1.11 \\
$\mathrm{RI} \%$ & 0.26 & 0.70 & 0.15 \\
$\mathrm{SiO}_{2} \%$ & 55.50 & 19.18 & 21.70 \\
$\mathrm{Fe}_{2} \mathrm{O}_{3} \%$ & 0.33 & 1.75 & 4.11 \\
$\mathrm{Al}_{2} \mathrm{O}_{3} \%$ & $\mathbf{4 1 . 4 0}$ & $\mathbf{6 . 4 4}$ & $\mathbf{1 . 5 2}$ \\
$\mathrm{CaO}$ total\% & 0.08 & 63.94 & 67.97 \\
$\mathrm{MgO} \%$ & 0.16 & 1.48 & 0.42 \\
$\mathrm{SO} \%$ & 0.00 & 3.50 & 2.34 \\
$\mathrm{Na}_{2} \mathrm{O}+\mathrm{K}_{2} \mathrm{O} \%$ & 0.00 & $0.90+0.52$ & $0.43+0.20$ \\
$\mathrm{Physical} \mathrm{Parameter}$ & & & \\
$\mathrm{Real} \mathrm{density}$ & 2.52 & 3.08 & 3.21 \\
$\left(\mathrm{~g} / \mathrm{cm}^{3}\right)$ & & & \\
$\mathrm{SEB}\left(\mathrm{m}^{2} / \mathrm{kg}\right)$ & 333 & 319 & 329 \\
$\mathrm{BET}\left(\mathrm{m}^{2} / \mathrm{kg}\right)$ & 9000 & - & - \\
\hline
\end{tabular}

mation, ${ }^{21}$ applied for non-isothermal conditions. Both metakaolin and kaolin were examined by XRD technique, using Siemens D-5000 diffractometer (BRUKER, Madrid, Spain) with $\mathrm{Cu} K_{\alpha}=1.54056 \AA$ radiation, equipped with a graphite monochromator (power settings of $40 \mathrm{kV}$ and $20 \mathrm{~mA}$ ). The scanning rate was $0.02^{\circ}$ in $2 \theta$ per second in the angular range of $2^{\circ}-100^{\circ}$ in $2 \theta$, Fig. 4 .

In addition, TEM and Selected-Area Electron Diffraction (SAED) techniques were applied. The sample preparation consisted of the following: the solid deposit was dispersed in butyl alcohol by ultrasonic wave technique to prevent particles agglomeration, then several drops were placed on $\mathrm{Cu}$ grids (coated with holey-carbon support film), dried and examined by JEOL microscope (JEM-2000 FX, $200 \mathrm{kV}$; National Microscopy Center, Madrid, Spain). The SAED data were collected in different zones of the TEM image, Figs. 5 and 6.

To demonstrate the chemical character of the resultant metakaolin, the $\mathrm{MK}+$ portlandite $+\mathrm{NaCl}$ aqueous suspensions were elaborated and continuously stirred for $4 \mathrm{~h}$ and 


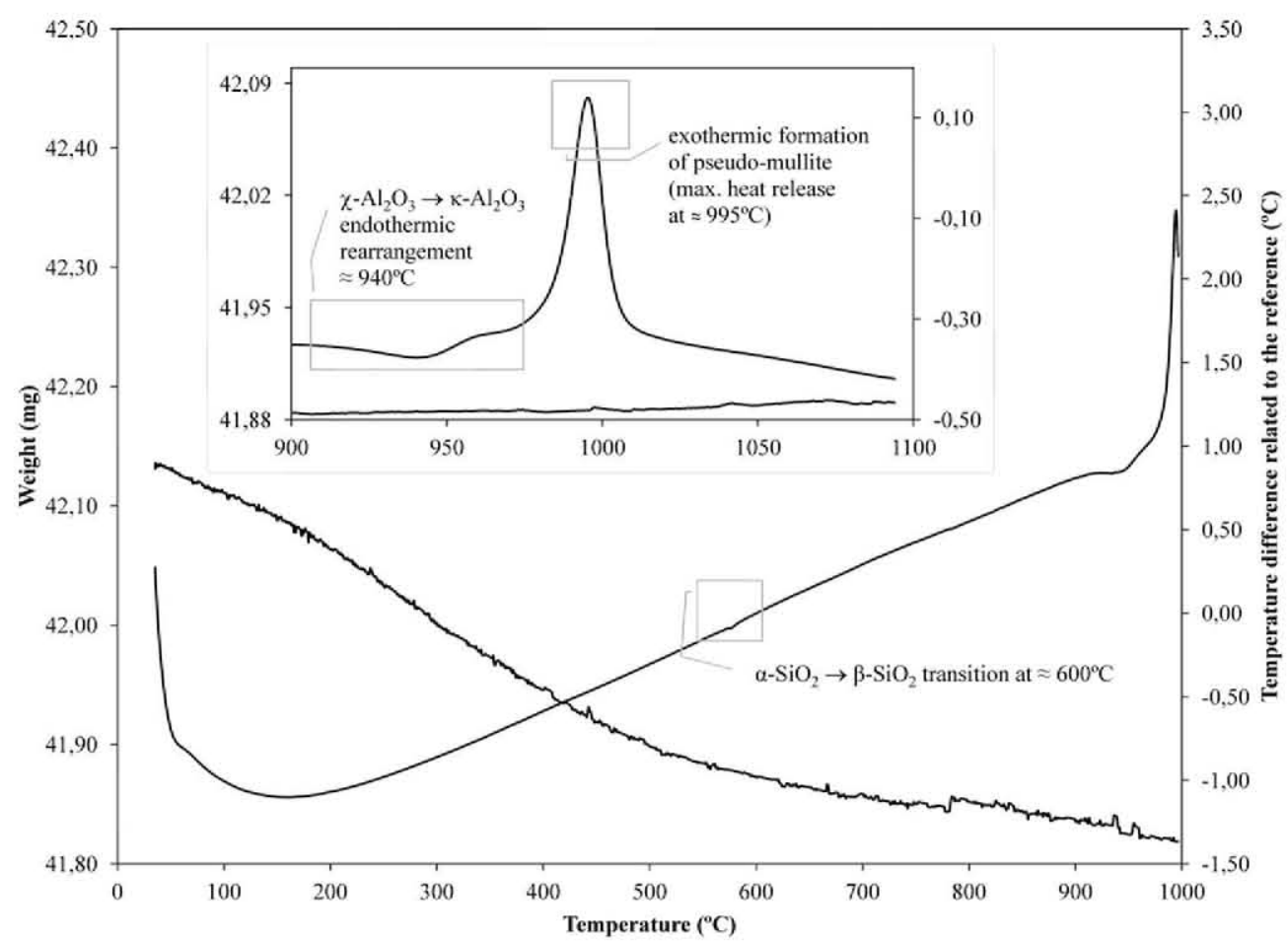

Fig. 2. Thermal decomposition of the MK sample. $0.84 \%$ total weight loss at $1000^{\circ} \mathrm{C}$.

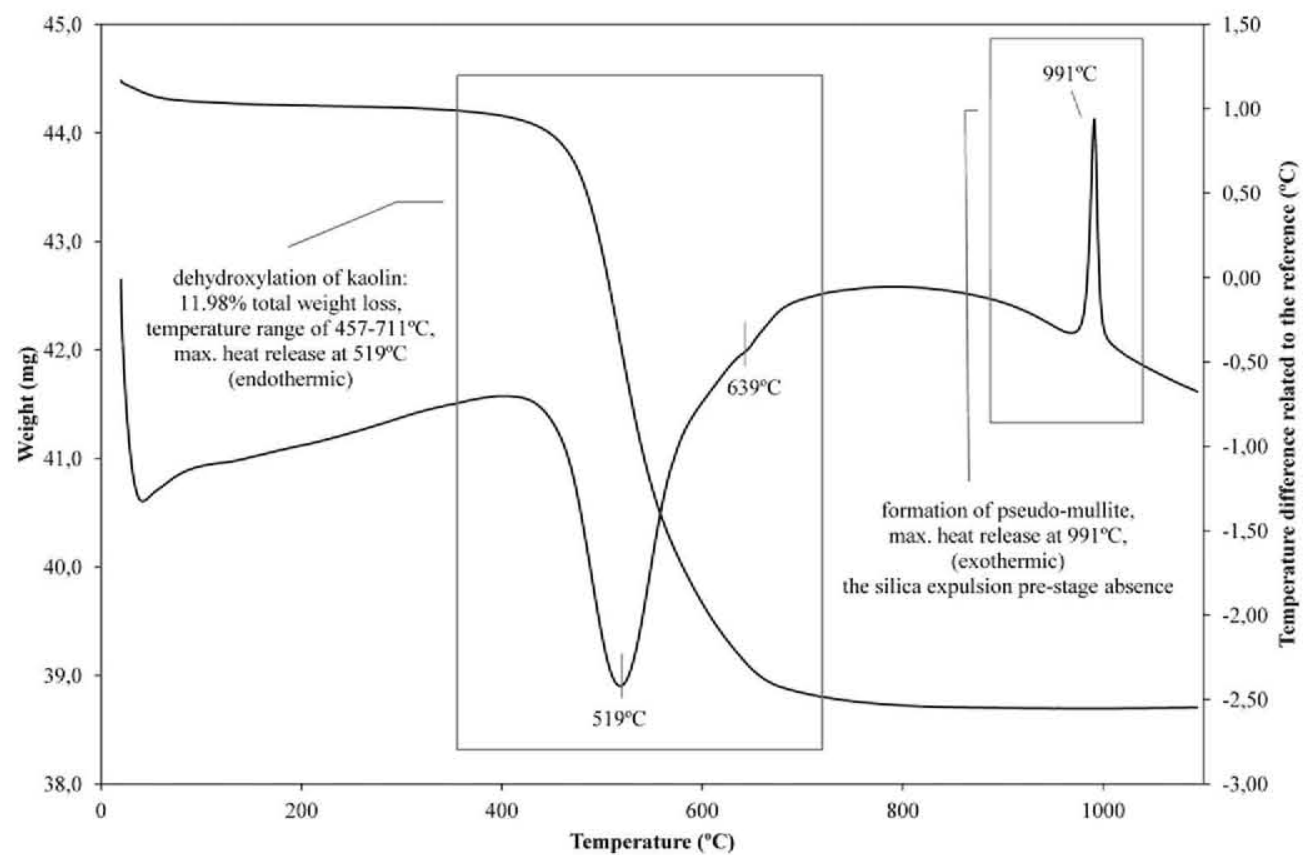

Fig. 3. Thermal decomposition of the kaolin.

7 days, separately. The reactive system was submitted to calcium hydroxide, $\mathrm{Ca}(\mathrm{OH})_{2}$, constant saturation and $3.75 \%$ $\mathrm{NaCl}$ solution was applied. The final solid parts of the experiment were analyzed qualitatively by XRD. The scanning rate was $0.05^{\circ}$ in $2 \theta$ per second at the angular range of $5^{\circ}-$ $70^{\circ}$ in $2 \theta$. The results can be observed in Fig 7.

\section{Results and Discussion}

(1) Chemical Composition and Frattini Results

The chemical composition of the MK is given in Table I. It presents principally its aluminous and siliceous nature according to the ASTM C618 standard. ${ }^{15}$ The pozzolanic activity results for the PC/MK blends are shown in Fig 1. As it can be observed, the MK exhibits extremely high chemical reactivity in all the analyzed $\mathrm{PC}$ blends already at 2 days of the experiment. Its correspondent $\mathrm{PC}$ hydration rate is raised vigorously, especially in the case of the $\mathrm{PC} 1$ blends during the first 7 days, consuming more $\mathrm{Ca}^{2+}$ than $\mathrm{OH}^{-}$ions. Moreover, this pozzolanic activity is more evident as the PC replacement ratio increases from 20 to $40 \mathrm{wt} \%$ in all the blended cements. However, such high, fast, and early MK activity in the case of the PC1 blends is so clear as in the PC2 blends. Some additional evolution of the hydration is noted 


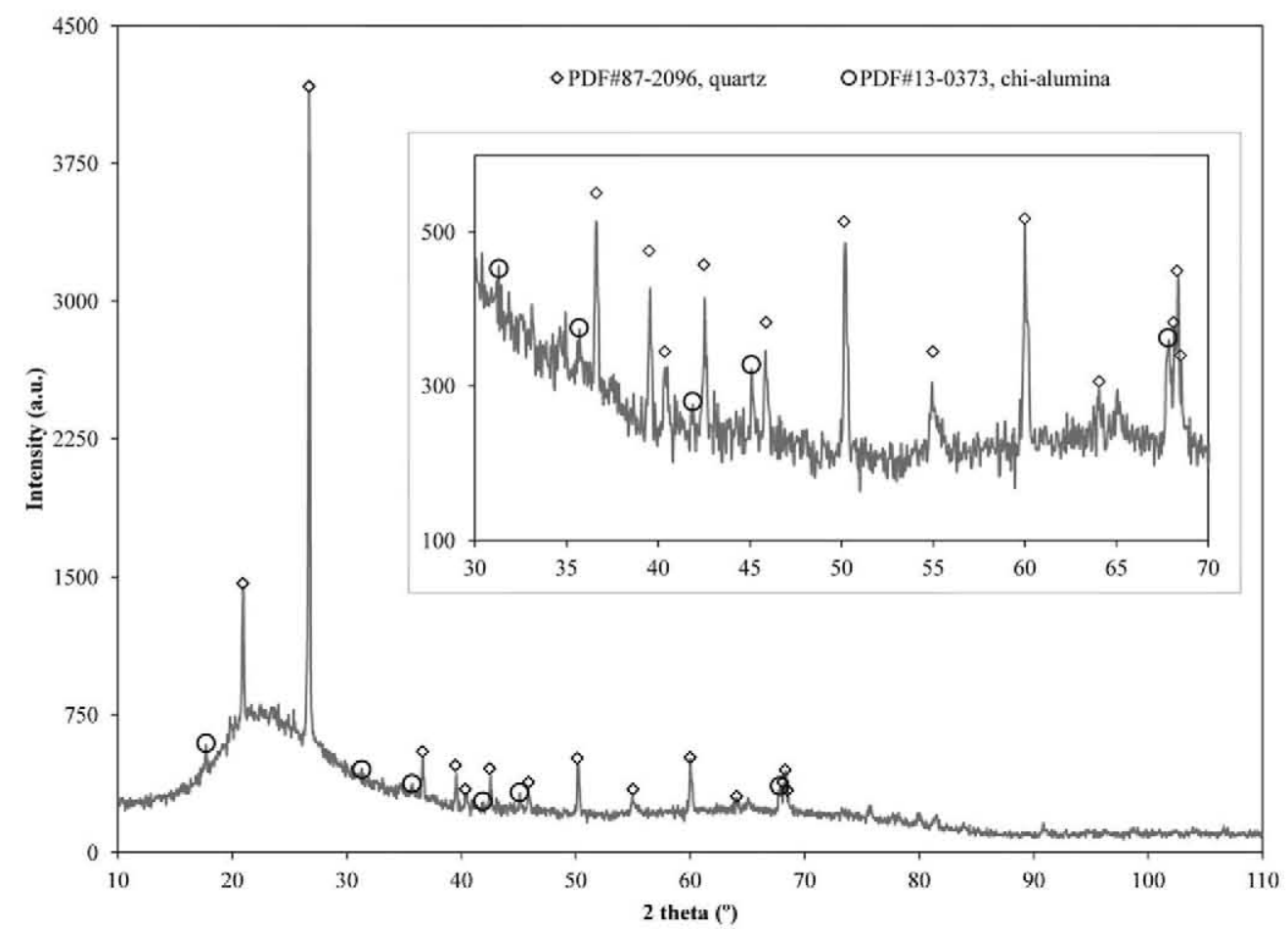

Fig. 4. XRD pattern of MK.
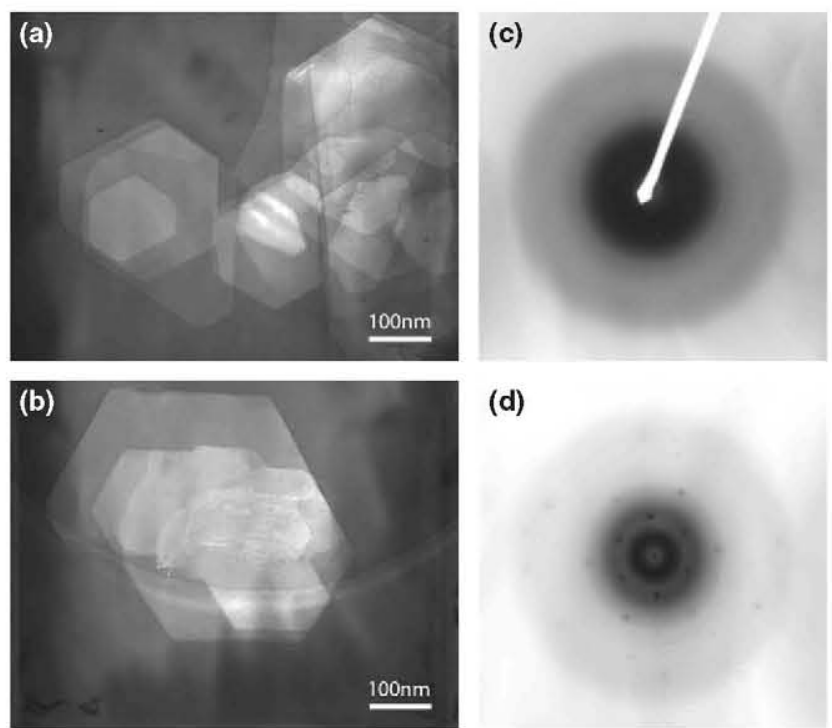

(d)

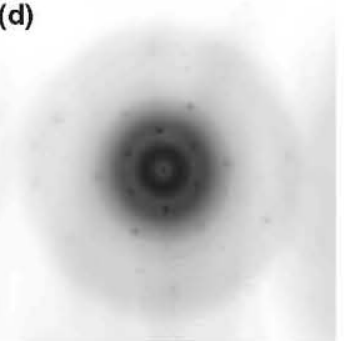

Fig. 5. TEM image of MK (a) Intimate amorphous mixture of $\mathrm{Al}+\mathrm{Si}$, (b) Thin crystalline/amorphous hexagonal sheets. SAED pattern of MK (c) Amorphous, (d) Amorphous/crystalline overlapped.

between 7 and 28 days, which means that, in this particular case, all the chemical reactions progress faster than for the $\mathrm{PC} 2$ cements. The reason for that is the difference in the $\mathrm{C}_{3} \mathrm{~A}$ content of both $\mathrm{PC} 1$ and $\mathrm{PC} 2$ mainly, i.e., $14 \%$ and $0 \%$, respectively. The $\mathrm{C}_{3} \mathrm{~A}$ phase is the most active OPC component from the others (PC1 case), which is additionally activated with the MK presence, especially at early age, promoting a chemical reaction series, competitive between each other. ${ }^{89}$ On the other hand, the MK action in the PC2 blends is limited only to $\mathrm{C}_{3} \mathrm{~S}$ amount, which is the most abundant constituent of OPC, but its hydration occurs more slowly as well as without any interaction with $\mathrm{C}_{3} \mathrm{~A}$ particles, (due to their absence; PC2 case). Therefore, the MK pozzolanic activity in the $\mathrm{PC} 2$ blends is more spectacular that
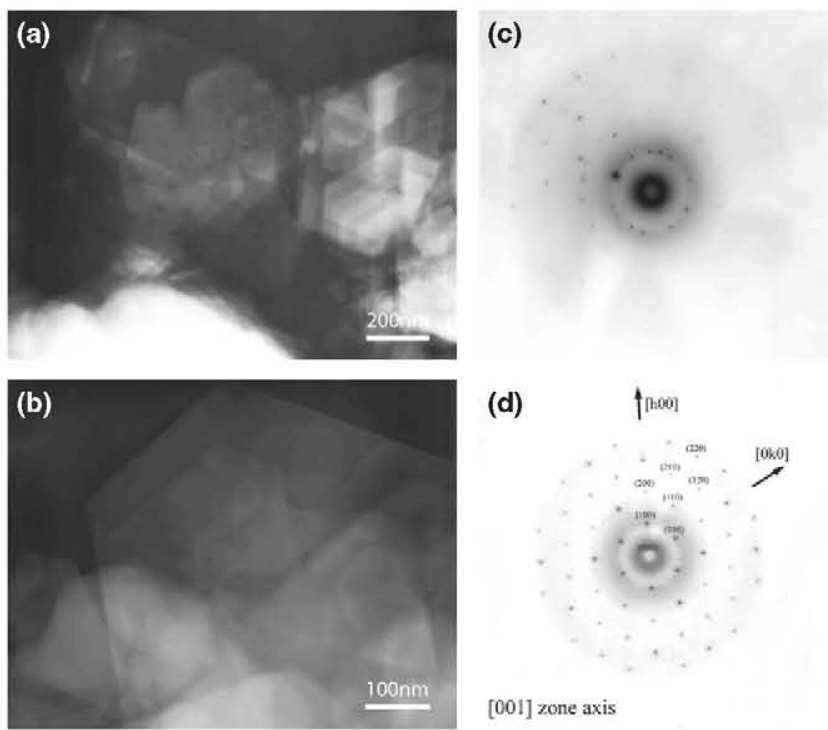

(d)

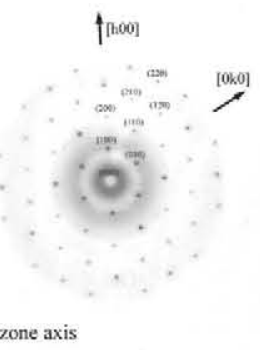

Fig. 6. TEM image of MK (a) Structure defects, (b) Hexagonal polycrystals. (c) SAED pattern of MK (polycrystalline). (d) Indexing of SAED pattern $(\mathrm{Al} / \mathrm{Si}=1) ;[001]$ zone axis.

in the $\mathrm{PC} 1$, producing a relatively great consumption of $\mathrm{Ca}^{2+}$ ions already at 2 days-age. However, for both cases, the results are very interesting, especially as the PC replacement ratio increases. Furthermore, different curve shapes can be observed, i.e., the $\mathrm{PC} 1 / \mathrm{MK}$ blends curve shape indicates somewhat steady consumption of calcium hydroxide combined with successive liberation of $\mathrm{Ca}(\mathrm{OH})_{2}$ from the PC1 hydration, competitive and correlated series of the hydration reactions. Nevertheless, in the $\mathrm{PC} 2 / \mathrm{MK}$ blends, between 2 and 7 days, a quite clear increase of [CaO] to the subsaturation state is noticed to decrease newly, but without any $\left[\mathrm{OH}^{-}\right]$consumption. It means that $\mathrm{Ca}(\mathrm{OH})_{2}$ released at 7 days-age from the $\mathrm{C}_{3} \mathrm{~S}$ (principally) component of the $\mathrm{PC} 2$ is immediately captured by the MK reactive particles, being captured more $\mathrm{Ca}^{2+}$ than $\mathrm{OH}^{-}$ions, (since the latter remains 


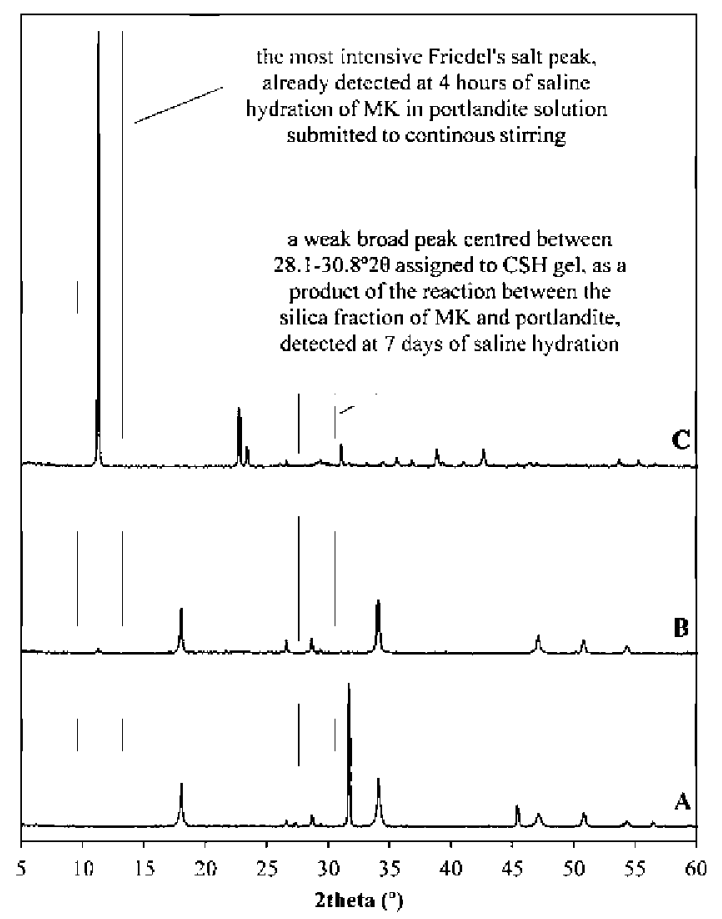

Fig. 7. Saline hydration of the MK samples submitted to $\mathrm{Ca}(\mathrm{OH})_{2}$, portlandite, and $3.75 \% \mathrm{NaCl}$ continuously stirred suspension during (a) $0 \mathrm{~h}$, (b) $4 \mathrm{~h}$, and (c) 7 days.

practically constant, within a framework of the each $\mathrm{PC} 2$ replacement obviously, up to the end of the test).

\section{(2) Thermal Analysis and XRD Diffraction}

The thermal analysis curves of MK, (TG/DTA), are present in Fig. 2. The total weight loss reached at $1000^{\circ} \mathrm{C}$ is $0.84 \%$ only. Two transitions are observed, i.e., the MK thermal decomposition curves show an endothermic effect at $940^{\circ} \mathrm{C}$ which is attributed to $\mathrm{SiO}_{2}{ }^{\mathrm{r}-}$ segregation and another one, subsequent to the former, exothermic change assigned to pseudo-mullite $\left(3 \mathrm{Al}_{2} \mathrm{O}_{3} \cdot 2 \mathrm{SiO}_{2}\right)$ formation which presents the maximum heat release at $995^{\circ} \mathrm{C}$, compatible with the previous observations. ${ }^{22}$ The thermal analysis results show a small presence of quartz, identified by the transition from $\alpha$-quartz to $\beta$-quartz at approximately $600^{\circ} \mathrm{C}$. However, it is clearly detected in the XRD pattern, (PDF\#87-2096), and seems to be the most abundant crystalline phase in the sample, which means that physicochemical state of the metakaolin is amorphous in predominance. On the other hand, some semi-crystalline/amorphous peaks are also observed and pre-identified as $\chi$-alumina phase (PDF\#13-0373, hexagonal system). The observed Bragg reflections and their assignation for the crystalline phases are given in Fig. 4.

Furthermore, the XRD pattern presents poorly crystalline character and diffuse distribution of some diffracted intensities is noticed. Hence, the first one well-defined Bragg's intensity $\left(16^{\circ}-34^{\circ} 2 \theta\right)$ is observed, as well as two others, highly diffused and less-evident than the former, $\left(34^{\circ}-45^{\circ} 2 \theta\right.$ and $52^{\circ}$ $-84^{\circ} 2 \theta$ ). Their presence testifies a high number of crystal imperfections of the kaolin precursor that lead to an increase in peak width and simultaneously a decrease in height, a case of the $\left(16^{\circ}-34^{\circ} 2 \theta\right)$ range especially. It corresponds to the overlapping of the different diffraction signals, which results optically in a distribution of the intensity around the Bragg peak widens, usually distorted both symmetrically and asymmetrically. On the other hand, if the diffuse intensity is distributed over the whole pattern, as in a case of the $\left(34^{\circ}-45^{\circ}\right.$ $2 \theta$ and $52^{\circ}-84^{\circ} 2 \theta$ ) ranges, it indicates a localized defects presence and that their positions are not correlated between each other (diffuse scattering). These two discussed diffuse intensity ranges are preliminarily assigned to $\mathrm{Si}$ tetrahedral and $\mathrm{Al}$ octahedral thermal regroupings of the kaolin, respectively. In other words, they represent the reactive silica, $\mathrm{SiO}_{2}{ }^{\mathrm{r}-}$, and reactive alumina, $\mathrm{Al}_{2} \mathrm{O}_{3}{ }^{\mathrm{r}-}$, fractions ${ }^{12}$ and their effect on the XRD pattern profiles. This observation will be correlated with the microscopic data presented in the next Sections.

\section{(3) TEM and SAED Observations}

The MK sample was analyzed by TEM to confirm its internal morphology and by SAED due to crystalline structure of the observed particles. The microscopic results show that the sample appears to consist of aggregations of long and, thin hexagonal sheets, which are $\approx 150-300 \mathrm{~nm}$ in overall diameter size, Figs. 5(a) and (b). However, in general, it displays compositional homogeneity in its morphology with a quite pronounced hexagonal texture, shown especially by the major particles. The hexagonals crystals present also somewhat exfoliated and ragged aspect, especially in the crystals borders, Figs. 5(a), (b) and 6(a). These morphological temperature alterations, which produce high reactivity on the crystals surface and diffusion are extremely beneficial for the chemical activation of kaolin, as it increases number of its dislocations, (contribution to reactive fractions of the pozzolan). Besides, aggregates of the sheets are different as the particles size increases to microscale giving a polycrystalline hexagonal aspect, as shown in Fig. 6(b). According to the XEDS scanning carried out supportively together with the microscopic results, the intimate mixture of $\mathrm{Al}$ and $\mathrm{Si}$ is found in all the analyzed parts of the sample, which may suggest a conservation of the original structure of the kaolin precursor, despite its thermal treatment. These results are conforming to the previous ones ${ }^{11}$ and suggest, moreover, that $\mathrm{Si}-\mathrm{O}$ tetrahedral sheets remain untouched or at least less-affected, even when dehydroxylation finalizes and temperature continues increasing up to $780^{\circ} \mathrm{C}$, as in this study. On the other hand, the $\mathrm{Al}$ atoms are expected to change their coordination to four and/or five-fold at the expense of its original six-fold Al coordination (kaolin), as proved by 10,13,23,24. Moreover and consequently, the six-fold $\mathrm{Al}$ coordination is possible to remain residually in the MK structure if any hydroxyl groups are kept. It can be confirmed by the TA analysis where a negligible weight loss up to the $1000^{\circ} \mathrm{C}(0.84 \%)$, Fig. 2, pointing no hydroxyls left from the thermal activation. Therefore, exclusively four and/ or five-fold $\mathrm{Al}$ atoms coordinations coexistence is suggested, as reported in the literature. ${ }^{13}$ This constant $\mathrm{Al} / \mathrm{Si}$ ratio and oxygen vacancies are beneficial and desirable for the chemical reactivity of any highly reactive $\mathrm{PC}$ substitute because of its contribution to PC hydration development, as demonstrated by the Frattini results, Fig. 1 and by other authors. ${ }^{8,9}$

\section{(4) Indexing of the SAED Patterns}

To determine the crystals geometry, a series of conventional SAED patterns were recorded from three different areas of the sample, Figs. 5 and 6 . Two types of SAED pattern are observed, ring and spot ones, both correspondent to different physicochemical state of the MK sample, i.e., amorphous, Fig. 5(c), crystalline, Fig. 6(d), and polycrystalline, Fig. 6(c). Their mutual superposition is captured as well, Fig. 5(d).

The Fig. 5(c) presents completely amorphous aspect of SAED pattern that consists of two diffuse rings that range between about $5.3 \AA$ and $2.6 \AA$ and $2.6 \AA$ and $1.4 \AA$, as well as a faint ring between $0.84 \AA$ and $0.66 \AA$ is also observed. These findings (observed Bragg distances) are consistent with those from XRD given in Fig. 4, where the former SAED ring corresponds to the diffuse scattering from the range of $18^{\circ}-36^{\circ} 2 \theta$ and also from 36 up to $70^{\circ} 2 \theta,(\lambda=1.54056 \mathrm{~nm})$. Although the rings appear jointly, some difference in their intensity aspect can be observed starting from $36^{\circ} 2 \theta(2.6 \AA)$, 
which is clearly confirmed by the XRD pattern. The range of $5.3-2.6 \AA$ is characterized by well-pronounced intensities of amorphous character assigned to Si tetrahedral, which should remain less affected during the activation than the $\mathrm{Al}$ octahedral fraction, giving both a homogenous mixture, but without amorphous silica detachment (occurred at higher temperature). The Fig. 5(a) corresponds to this amorphous pattern and presents particles of about $100 \mathrm{~nm}$ in their smallest dimension, as well as demonstrates their irregular shape. This fraction is the most attractive part for the very important pozzolanic properties of the MK. In addition, as the edge dislocations of the Al octahedral are more significant than in a case of the Si tetrahedral, as shown by these findings, as well as the $\mathrm{Si}$ atoms do not suffer any coordination change, while the $\mathrm{Al}$ atoms do, the most reactive fraction from the pozzolanic activity point of view must be reactive alumina, aside from the fact that reactive silica is quantitatively major in this case. However, the $\mathrm{Al}_{2} \mathrm{O}_{3}{ }^{2-}$ and $\mathrm{Al}_{2} \mathrm{O}_{3}{ }^{-}$fractions possess qualitatively major chemical affinity to originate privileged reactions (ettringite ${ }^{7,8,12}$ or Friedel's salt ${ }^{9}$ formation).

The Fig. 5(d) shows again an amorphous aspect of the hexagonal in form of diffuse ring at the range between the following limits, starting with the most external: $1.33 \AA$, $1.82 \AA, 2.25 \AA$ and $4.00 \AA$. These values are consistent with those found in Fig. 5(c), although a crystalline phase of hexagonal kind is superposed on the plane. Moreover, the particles aspect is unchanged in form, but major in diameter than in the previous case, as it is shown in its respective SAED pattern, Fig. 5(b). These observations indicate a presence of non-activated and unbroken structure of kaolin together with irregular metakaolin particles. Hence, the diffuse/crystalline signals collapse is observed.

The Figs. 6(a)-(c) present TEM and SAED results for polycrystalline fraction of the metakaolin. The microphotographs show pseudo-hexagonal structure with numerous crystal defects of different kind, the particles are about 200 $500 \mathrm{~nm}$ in diameter and the SAED pattern present both polycrystalline and crystalline character. The polycrystalline rings are about $1.29 \AA$ and $2.22 \AA$ in diameter, which corresponds to two of the diffuse rings shown in the Fig. 5(d). This points that the same structure is observed; however, in different atoms arrangement, both disordered (amorphous) and semi-organized (polycrystalline).

Finally, the last SAED pattern, Fig. 6(d), shows exclusively crystalline character for which the XEDS scanning was performed giving the $\mathrm{Al} / \mathrm{Si} \approx 1$ ratio approximately. The $\mathrm{SAED}$ reflections were successfully confronted with the hexagonal $\chi$ alumina crystallographic data $^{25}$ and are given in Table II. Based on these findings, the [001] zone axis is computed, Fig. $6(\mathrm{~d})$. The indicated presence of near- $\chi$-alumina structure in the kaolin thermal decomposition product, as shown by the SAED results, remains in a good agreement with the XRD and TA data. However, it is reported for the first time in the literature. The interplanar spacings measured of the pattern are also compared with the reflections obtained from the XRD d-values as well as with these delivered from the authors. ${ }^{25}$ A good agreement is obtained, although the literature offers limited possibility of reference in this very case. In addition, the crystallographic data of quartz (minor mineralogical component of MK) to comparison were included as well, Table II. It also exhibits a proximity to the SAED findings as $\chi$-alumina; however, the angles between the particular $d$-spacing plains do not remain in satisfactory agreement, as it would have been expected, Table II.

\section{(5) Final Considerations}

According to the XRD results, an approximate degree of crystal breakdown was calculated using the following ratio: $\left(I_{0}-I\right) / I_{0}$, where $I_{0}$ is XRD peak intensity of a given crystalline phase and $I$ is a XRD peak intensity of the same phase after its thermal activation and structure rupture. Hence, taking into consideration the XRD pattern for kaolin and metakaolin, (reflection at $7.18 \AA$; the same experiment conditions), $96 \%$ of crystal breakdown degree is obtained. In addition, the kinetics study carried out for the dehydroxylation process of the kaolin at the temperature range of $457^{\circ} \mathrm{C}$ $-711^{\circ} \mathrm{C}$, Fig. 3 , has permitted to distinguish its two stages, although overlapped. The first one is responsible for the principal water loss, whereas the second subtle change is where the stronger bounded water molecules are detached. Independently, both the intervals respond to the random

Table II. Indexing of the SAED Pattern Given in Fig. 6(d).[d $d_{\text {hkl }}(\AA)$ and $\left.\varphi\left({ }^{\circ}\right)\right]$

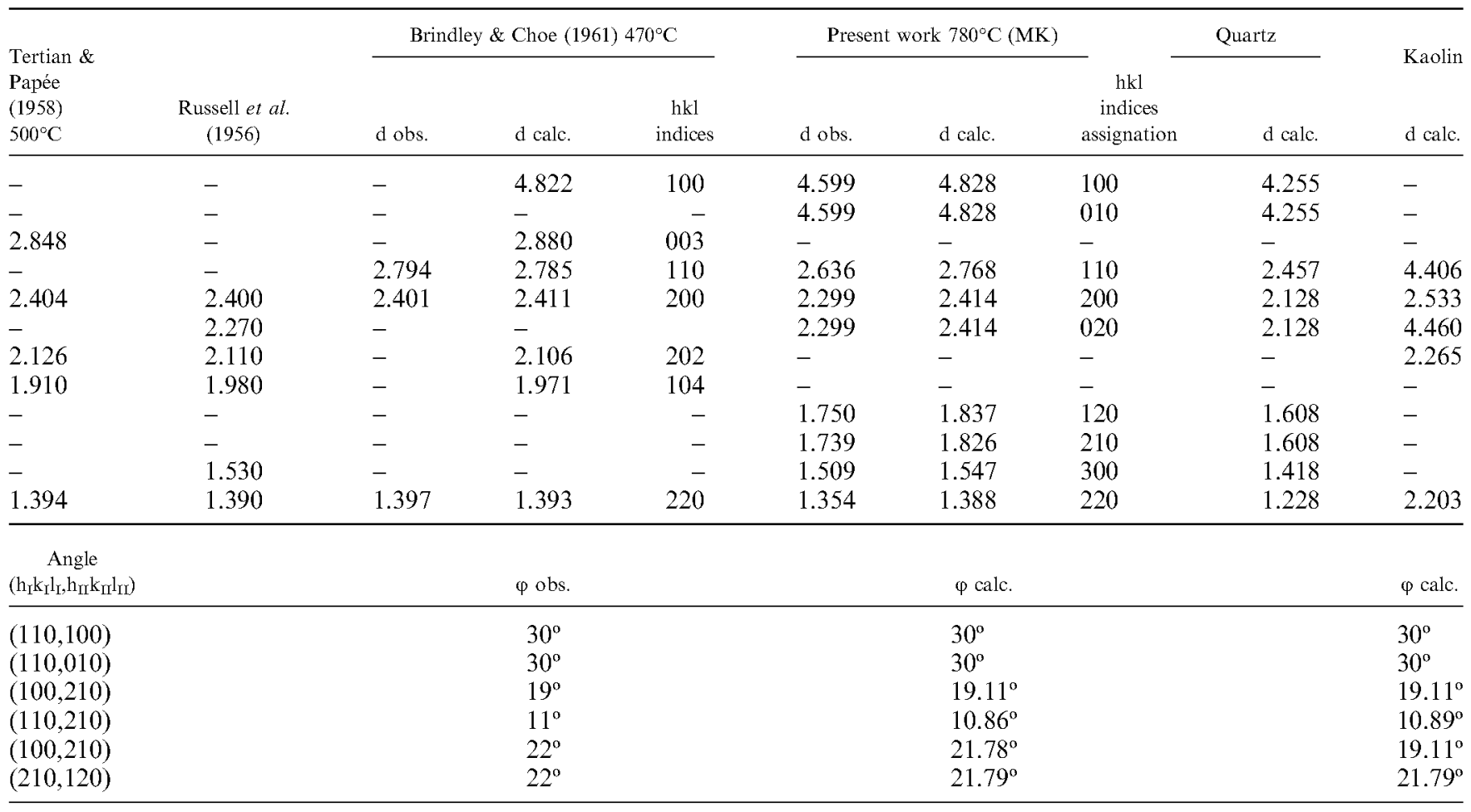


nucleation kinetic models, A3 and F2, (Avrami and secondorder reaction, respectively), i.e., simultaneous occurrence of diffusion and phase-boundary control mechanisms. Therefore, the detachment of $\mathrm{H}^{+}$and its subsequent union to another $\mathrm{OH}^{-}$group, to be finally released from the kaolin structure as water molecule, occurs heterogeneously. If $\mathrm{H}^{+}$ bonds to another $\mathrm{OH}^{-}$than the closest, the inner $\mathrm{OH}^{-}$, the process is kinetics-dependent and an additional water pressure is generated inside the structure. On the other hand, the kaolin dehydroxylation may be controlled by thermodynamic effects, as not all the parts of the structure receive the same energy packet to break their bonds, producing extra protons and anions migrations and enhancing water pressure through the interior. Hence, highly defective structure finally collapses, but maintaining its original tendency. Some part can be transformed into crystalline phase, as occurring in this study, since the mentioned $\chi$-alumina-like structure is detected, probably developed by means of the aid of the water pressure from the kaolin dehydroxylation. In addition and because of the same reason, the polycrystalline aspects of the resultant metakaolin are observed. In summing up, not all the fraction of kaolin structure is activated in the same degree and the dehydroxylated material contains amorphous, polycrystalline and crystalline parts. However, the amorphous fraction $\left(\mathrm{SiO}_{2}{ }^{\mathrm{r}-}+\mathrm{Al}_{2} \mathrm{O}_{3}{ }^{\mathrm{r}-}\right.$ mainly) must be predominant and, for this reason, the chemical character of the MK is aluminic ${ }^{12}$ due to the high kaolin's crystal structure breakdown ( $96 \%$ of reactive fraction from the kaolinite crystalline phase origin, estimated by XRD data), Fig. 1.

According to the $\mathrm{e}^{13}$ and as a contribution to this pioneer research carried out on the kaolin rock from the same origin as used in the study, it can be claimed that the $780^{\circ} \mathrm{C}$ obtained metakaolin must be at its most metastable state, i.e., it must possess the $\mathrm{Al}^{3+}$ coordination abundance of both $\mathrm{AlO}_{4}$ and $\mathrm{AlO}_{5}$, which results in extremely high chemical reactivity of this fraction, as demonstrated in the previous work. $^{79,12}$ On the other hand, for comparison, more significant amount of the Si tetrahedral part should be less reactive from the chemical point of view. It remains consistent with the previous research, ${ }^{13}$ where the signal correspondent to the Si tetrahedral sheets breakdown is not observed before $900^{\circ} \mathrm{C}$ to be finally expulsed as a nuclei of mullite is being formed, i.e., the $\mathrm{AlO}_{6}$ coordination is reestablished. In the TA results, this $\mathrm{Si}$ tetrahedral structure rupture contributes to the endothermic signal at $940^{\circ} \mathrm{C}$, Fig. 2, which is not observed in case of the thermal decomposition of the pure kaolin material, Fig. 3. This finding confirms the other observations $^{13}$ and permits to assign the silica fraction segregation directly to the mullite formation signal at $991^{\circ} \mathrm{C}$, Fig. 3. The altered kaolin structure after its thermal treatment for $24 \mathrm{~h}$ (the MK sample) enhances the silica expulsion before the $\mathrm{AlO}_{6}$ coordination is re-achieved.

In summing up, the MK obtained in this study, destined as Portland cement partial substitute, is characterized by a highly deformed Al tetra- and penta-coordinated aluminous fraction, which predominates over practically regular Si tetrahedral sheets, built mostly by $\mathrm{Q}^{4}(1 \mathrm{Al})$ and $\mathrm{Q}^{4}(0 \mathrm{Al})$ arrangements. ${ }^{13,26}$ Hence and as a final demonstration, the MK shows its aluminic chemical character already at initial hours when submitted to saline hydration $(\mathrm{NaCl})$ in calcium hydroxide suspension, studied for the purpose at $4 \mathrm{~h}$ and 7 days, Fig. 7. Taking into consideration the reactive silica and reactive alumina parameter values for the $\mathrm{MK}, 48.5$ and $29.0 \%$, respectively, ${ }^{8}$ the $\mathrm{Al}_{2} \mathrm{O}_{3}{ }^{\mathrm{r}-}$ fraction starts to react already at $4 \mathrm{~h}$, forming the first crystals of Friedel's salt, i.e., it detaches from the altered thermally structure, activated by $\mathrm{Ca}(\mathrm{OH})_{2}$ and $\mathrm{NaCl}$ reagents. However, no visible $\mathrm{SiO}_{2}{ }^{\mathrm{r}-}$ action is observed during the first $4 \mathrm{~h}$ of the experiment, although it predominates quantitatively. But the CSH gel presence ${ }^{27}$ is clearly shown at 7 days of the saline hydration, Fig. 7, although it is expected to start forming once the $\mathrm{Al}_{2} \mathrm{O}_{3}{ }^{\mathrm{r}-}$ fraction is separated from the $\mathrm{SiO}_{2}{ }^{\mathrm{r}-}$ one, as logical.
Furthermore, the reactive alumina found in the MK is different from this investigated in fly ash or another volcanic glasses with pozzolanic properties as well, i.e., it is present in vitreous physicochemical state for the latter, which means that it possesses mechanical hardness and needs to be dissolved first to react with portlandite, $\mathrm{Ca}(\mathrm{OH})_{2}$, originated from $\mathrm{PC}$ hydration. ${ }^{9}$ Hence, the same action scheme for these parameters, $\mathrm{SiO}_{2}{ }^{\mathrm{r}-}$ and $\mathrm{Al}_{2} \mathrm{O}_{3}{ }^{\mathrm{r}-}$, in these conditions is predicted not to be equal for all pozzolans as previously shown for some of them,${ }^{8}$ neither for those from the equivalent clayey origin (i. e., spheroidal pearlite), as their particular chemical character depends, regardless of each material physicochemical history, on atoms arrangement and correlation of their coordination as well as on the presence/absence in the blend of other crystalline additions as fillers, ${ }^{28}$ as the pozzolan $\mathrm{SiO}_{2}{ }^{\mathrm{r}-} / \mathrm{Al}_{2} \mathrm{O}_{3}{ }^{\mathrm{r}-}$ quantitative ratio will be substantial only in a lesser extent.

\section{Conclusions}

Taking into a special consideration the cement industry needs, the kaolin material was dehydroxylated obtaining metakaolin. The material structure conserves its "crystalline memory" and presents a polycrystalline near- $\chi-\mathrm{Al}_{2} \mathrm{O}_{3}$ metastable as well as polymorphic aspect. The total kaolin crystals breakdown has been estimated to be of $96 \%$.

The reactive silica, $\mathrm{SiO}_{2}{ }^{\mathrm{r}-}$, fraction provided from the kaolin structure is found neither to be segregated nor especially deformed. Moreover, its state does not affect the Al octahedral sheets thermal development and vice versa, the new correlation of $\mathrm{Al}$ coordination, $\mathrm{Al}_{2} \mathrm{O}_{3}{ }^{\mathrm{r}-}$, (tetra- and penta-) does not deform the Si tetrahedrals significantly.

The crystalline phase found in the SAED pattern of the metakaolin is indexed as $\chi-\mathrm{Al}_{2} \mathrm{O}_{3}$ phase observed from the [001] zone axis, the finding which is reported for the first time in literature as correspondent to kaolin dehydroxylation process.

The Talero's classification of pozzolanic additions realized in function of their chemical character is once again exposed as the only reliable manner to define their possible behavior in cement pastes, mortars and concretes in front of sulfate and chloride attacks, separately. This chemical character can be aluminic, silicic or an aleatory combination of these two extremes ( $\mathrm{SiO}_{2}{ }^{\mathrm{r}-}$ and $\mathrm{Al}_{2} \mathrm{O}_{3}{ }^{\mathrm{r}-}$ components) i.e., silicic-aluminic for those with silicic chemical character predominant over the aluminic one, and on the contrary, aluminicsilicic, for the opposite reason. The chemical character of pozzolan is independent from its origin (natural or artificial) and nature (siliceous or aluminous, according to ASTM C618).

The chemical character of the metakaolin is aluminic being based on its high reactive alumina, $\mathrm{Al}_{2} \mathrm{O}_{3}{ }^{\mathrm{r}-}$, content, $(29.0 \mathrm{wt}$ $\%{ }^{8}$ ), even despite the higher content of reactive silica, $\mathrm{SiO}_{2}{ }^{\mathrm{r}-}$, $\left(48.5 \mathrm{wt} \%^{8}\right)$. The chemical character of pozzolans is expected to be more related to their crystals structure history and also to their specific atoms coordination than it can depend on their reactive parameters (mostly $\mathrm{SiO}_{2}{ }^{\mathrm{r}-}$ and $\mathrm{Al}_{2} \mathrm{O}_{3}{ }^{\mathrm{r}-}$ ) ) quantitative ratio.

\section{Acknowledgments}

The authors are grateful to the Instituto de Ciencias de la Construcción "Eduardo Torroja-CSIC for supplying all the necessary materials, as well as to the ICTS Centro Nacional de Microscopia Electrónica, Universidad Complutense de Madrid for all the indispensable instrumental techniques and to Dr. Esteban Urones Garrote for his kind and valuable assistance during the measurements. Research supported by Technical University of Madrid (Spain), Ph.D. grant No. RR01/2008 (L. Trusilewicz).

\section{References}

${ }^{1}$ H. F. W. Taylor, Cement Chemistry. Academic Press Ltd., London, 1990. ${ }^{2}$ M. Murat and M. Dripuche, "Chemical Reactivity of Thermally Activated Clay Minerals. Estimation by Dissolution in Hydrofluoric Acid," Cem. Concr. Res., 18 [2] 221-8 (1988). 
${ }^{3}$ F. M. Lea and C. H. Desch, "Química del Cemento y del Hormigón"; pp. 130-131 in Cement and Concrete Chemistry, 3rd ed., Edward Arnold Publisher, London, 1970.

${ }^{4}$ J. Ambroise, S. Martin-Calle, and J. Pera, "Pozzolanic Behavior of Thermally Activated Kaolin"; pp. 731-748 in 4th CANMET/ACI Int. Conf. on Fly Ash, Silica Fume, Slag and Natural Pozzolans in Concr., Edited by V. M. Malhotra. SP-132. CANMET/ACI, Istanbul, Turkey, 1992.

${ }^{5}$ A. López Ruiz, Determinación Experimental Rápida de las Condiciones Optimas de Activación de Arcillas Para su Transformación en Puzolanas Artificiales, ("Experimental and Fast Determination of Optimal Conditions Applied for Clays Activation with a Purpose to Their Transformation Into Artificial Pozzolans"), Monograph No. 85. Laboratorio Central de Ensayo de Materiales de Construcción (CEDEX), Madrid, 1995.

${ }^{6}$ A. López Ruiz, Posibilidades de Empleo de las Arcillas en la Fabricación de Aglomerantes Económicos, ("Possibilities of Clays use in Economical Conglom erates Manufacturing"), Monograph No. 84. Laboratorio Central de Ensayo de Materiales de Construcción (CEDEX), Madrid, 1995.

R. Talero, "Expansive Synergic Effect of Ettringite From Pozzolan (Metakaolin) and From OPC, co-Precipitating in a Common Plaster-Bearing Solution. Part I: By Cement Pastes and Mortars," Constr. Build. Mater., 24 [9] 1779-89 (2010)

${ }^{8}$ R. Talero, "Expansive Synergic Effect of Ettringite From Pozzolan (Metakaolin) and From OPC, co-Precipitating in a Common Plaster-Bearing Solution. Part II: Fundamentals, Explanation and Justification," Constr. Build. Mater., 25 [3] 1139-58 (2011).

${ }^{9}$ R. Talero, L. Trusilewicz, A. Delgado, C. Pedrajas, R. Lannegrand, V. Rahhal, R. Mejía, S. Delvasto, and F. A. Ramírez, "Comparative and SemiQuantitative XRD Analysis of Friedel's Salt Originating From Pozzolan and Portland Cement," Constr. Build. Mater., 25 [5] 2370-80 (2011)

${ }^{10} \mathrm{G}$. W. Brindley and M. Nakahira, "The Kaolinite-Mullite Reaction Series: I, A Survey of Outstanding Problems," J. Am. Ceram. Soc., 42 [7] 311-4 (1959).

${ }^{11}$ R. W. Grimshaw, The Chemistry and Physics of Clays and Other Ceramic Materials. Ernest Benn Limited, London, 1971.

${ }^{12} \mathrm{R}$. Talero, "Contribution to the Analytical and Physical-Chemistry Study of the Ternary System: Pozzolanic Cements-Gypsum-Water"; Ph.D. Thesis, Universidad Complutense de Madrid, Chemical Science Faculty, Madrid, Spain, 1986.

${ }^{13}$ S. Moya, J. Sanz, J. M. Serratosa, A. Madani, and S. Aza, "Aluminum-27 and Silicon-29 Magic-Angle Spinning Nuclear Magnetic Resonance Study of the Kaolinite-Mullite Transformation," J. Am. Ceram. Soc., 71 [10] C418-21 (1988).

${ }^{14}$ EN 197-1:2011 Standard, Cement: Composition, Specifications and Conformity Criteria for Common Cements. Spanish Association for Standardization and Certification - AENOR, Madrid, Spain, 2011
${ }^{15}$ ASTM C 618-95a, Standard Specification for fly ash and raw or Calcined Natural Pozzolan for use as Mineral Admixture in Portland Cement Concrete. Annual book of ASTM Standards, Vol. 04.02. ASTM International, West Conshohocken, PA, 1994.

${ }^{16}$ EN 196-5:2005 Standard. Methods for Testing Cement. Part 5: Pozzolanicity Test for Pozzolanic Cements. AENOR, Madrid, Spain, 2005.

${ }^{7}$ Instrucción Para la Recepción de Cementos RC-08 (R.D. 956/2008, 06/06 2008), Cement Acceptance Instruction RC-08. Spanish Association for Standardization and Certification - AENOR, Madrid, Spain, 2008.

${ }^{18}$ ASTM C311-07. Standard Test Methods for Sampling and Testing fy ash or Natural Pozzolans for use in Portland-Cement Concrete. Annual book of ASTM Standards, Vol. 04.02, ASTM International, West Conshohocken, PA, 2007.

${ }^{9}$ EN 196-2:2005 Standard, Methods of Testing Cement. Chemical Analysis of Cement. Spanish Association for Standardization and Certification AENOR, Madrid, Spain, 2005.

${ }^{20}$ RC-75, Pliego de Prescripciones Técnicas Generales Para la Recepción de Cementos, 1975 (Decreto de la Presidencia del Gobierno 1964/1975 de 23 de mayo), B.O.E., No. 206, 1975.

${ }^{21}$ A. W. Coats and J. P. Redfern, "Kinetic Parameters From Thermogravimetric Data," Nature, 201, 68-9 (1964).

${ }^{22} \mathrm{R}$. C. Mackenzie, The Differential Thermal Investigation of Clays. Mineralogical Society, London, 1957.

${ }^{23} \mathrm{~S}$. Iwai, T. Nagai, and T. Shimamune, "Untersuchung des Vorgangs de Strukturveränderung des Dickits bei Entwässerung," Acta Crystallogr. Sect. B, 27, 248-50 (1971).

${ }^{4}$ K. J. D. MacKenzie, I. W. M. Brown, R. H. Meinhold, and M. E. Bowden, "Outstanding Problems in the Kaolinite-Mullite Reaction Sequence Investigated by ${ }^{29} \mathrm{Si}$ and ${ }^{27} \mathrm{Al}$ Solid-State Nuclear Magnetic Resonance: I, Metakaolinite," J. Am. Ceram. Soc., 68 [6] 293-7 (1985).

${ }^{25}$ G. W. Brindley and J. O. Chloe, "The Reaction Series, Gibbsite $\chi$-Alumina K-Alumina Corundum," Am. Mineral., 46 [12] 771-85 (1961).

${ }^{26} \mathrm{~A}$. Fernández-Jiménez and A. Palomo, "Caracterización del Cemento por ${ }^{29} \mathrm{Si}$ and ${ }^{27} \mathrm{Al}$ RMN-MAS. Estado del Arte", ("Cement Characterization by Means of ${ }^{29} \mathrm{Si}$ and ${ }^{27} \mathrm{Al}$ RMN-MAS. State of the art")," Cemento y Hormigón, 936, 12-20 (2010)

${ }^{27}$ G. Renaudin, J. Russias, F. Leroux, F. Frizon, and C. Cau-dit-Coumes, "Structural Characterization of $\mathrm{C}-\mathrm{S}-\mathrm{H}$ and $\mathrm{C}-\mathrm{A}-\mathrm{S}-\mathrm{H}$ Samples - Part I: LongRange Order Investigated by Rietveld Analyses," J. Solid State Chem., 182 [12] 3312-9 (2009)

${ }^{28}$ V. Rahhal, V. Bonavetti, L. Trusilewicz, C. Pedrajas, and R. Talero, "Role of the Filler on Portland Cement Hydration at Early Ages," Constr. Build. Mater., 27 [1] 82-90 (2012). 